\title{
Analysis of the Collaborative Education System of Local Universities under the Fundamentals of "New Engineering" Construction
}

Jing $\mathrm{Ma}^{1,2,3 *}$

${ }^{1}$ School of Mechanical and Automotive Engineering, Qilu University of Technology, Jinan 250031, Shandong Province, China;

${ }^{2}$ Shandong Academy of Sciences, Jinan 250031, Shandong Province, China;

${ }^{3}$ Shandong Institute of Mechanical Design and Research, Jinan 250031, Shandong Province, China

\begin{abstract}
Based on the fundamentals of "new engineering" construction, this article briefly introduces the development standards of local colleges and universities, analyzes the significance of the collaborative education system of local universities under the fundamentals of "new engineering" construction, and explores the fundamentals of "new engineering." The specific implementation strategy of the collaborative education system of industry-university collaboration in local colleges and universities.
\end{abstract}

Keywords: "New engineering"; Local colleges and universities; Industry-university cooperation; Model exploration

Publication date: May, 2021; Publication online: 31 May, 2021

*Corresponding author: Jing Ma, majing19881@163.com

\section{Introduction}

Addressing the latest mission, "new requirements and new challenges of modern education," "new engineering" will focus on the future of engineering education and will pay more attention to innovation and research works. In the development of the new era, the establishment of "new engineering" has been comprehensively deployed. Developing innovative talents who will lead the future technology fields and industries has become a consensus. Building the "new engineering" field is an important part of enhancing the improvement of local institutes and developing talents. In this case, it needs to be closely integrated with various educational disciplines to effectively achieve the educational goals in the "new engineering" field. Additionally, establishing new talents and developing outstanding models under the collaborative training mechanism allows to cope with the current challenges of network engineering education. Cao Jianfang ${ }^{[1]}$ proposed to enhance industry-university collaboration, build professional system education resources, and improve the engineering training level of college teachers and "new engineering" talents. Therefore, this establishes a "dual-professional" faculty team, implements a "dual-teacher system," strengthen process evaluation, promote the enhancement of network engineering professional courses, and promote talents' innovation as well as entrepreneurship. Liu Lili ${ }^{[2]}$ pointed out that we should actively respond to the needs of regional economic, social development and technical innovation of companies which strengthens the integration of industry and education, the development of industrial-university collaboration, and the construction of "new engineering" fields. Thus, the goal is to establish talents with engineering practical skills who are well versed in industrial development. In the context of the establishment of the "new engineering" field, Liu $\mathrm{Jia}^{[3]}$ pointed out that local universities should focus 
on promoting the improvement and innovation of existing engineering majors by promoting the enhancement of engineering training methods and further strengthening industrial-university collaboration.

\section{The Fundamentals and Characteristics of} "New Engineering" Construction

\subsection{The fundamentals of "New Engineering" construction}

On February 18, 2017, the Ministry of Education held a seminar on the development strategy of higher engineering education in Fudan universities. The meeting discussed the meaning and characteristics of "new engineering," as well as its construction and development methods. In order to meet the high requirements represented by new technologies, new forms, new models, and new industries, we need to accelerate improvement and innovation in the field of engineering technology. On April 8, 2017, the Ministry of Education held a seminar on the construction of the "New Engineering Course" in Tianjin Colleges and Universities. "New engineering" construction goals are to explore the formation of a "new engineering" construction model by 2020 , actively adapting to the development of new technologies and new industries, build a model organization with Chinese characteristics by 2030, transform the engineering education system, as well as vigorously supporting the country. Thus, the innovation and development of world-class engineering education model will be in China.

\subsection{Analysis of characteristics of "new engineering"}

Based on the "new engineering" concept, the analysis on the characteristics of current university education systems are as follows. Firstly, instill and integrate liberal arts and sciences, and amend the circumstance of specific employment scope and detailed knowledge of basic theories. Secondly, the purpose of education is to spread knowledge and pay more attention to skill training. Finally, it is about undergraduate engineering education to train basic talents, whereby the training targets are senior engineering and technical talents, thus adopting the credit system and establishing a quality assurance system represented by university evaluation and engineering education certification.

\section{Development Standards of Local Colleges and Universities}

\subsection{Poor teaching quality and outdated teaching strategies}

Although the current high-quality education advancement has made considerable progress, but the old education situation still exists. For example, teachers only participate in the process of conducting teaching activities and talents only complete tasks so that they can graduate successfully. This kind of learning is difficult to guarantee the good quality education, and in the long-term development, this will lead to a bottleneck period in the advancement of universities.

\subsection{Monotonous teaching method and the unconvincing teaching evaluation system}

Teaching method is an important factor to improve the quality of teaching, but the current teaching methods used in colleges and universities mainly emphasize the intellectual independent learning among teachers and talents. Thus, it leads to a lack of participation of talents, fails to deliver the basic knowledge of lessons, creates anxiety about learning, and ultimately leads to continuous decrease in quality education. Since education evaluation is a key link of college education, it directly affects the progression of college education; therefore, it is necessary to use education evaluation as a guide to rapidly achieve the goal of quality education. However, at the current level of college and university education, teachers do not pay attention to the results of teaching evaluation, thus lowering the standards of teachers and ultimately leading to an educational imbalance.

\subsection{Unstable courses and curriculum}

Due to the lack of a thorough understanding of the school's necessary employment skill training plan and teaching method, it is impossible to establish a 
stable quality education based on the school's teachings which is supposed to cater to the employment needs of companies and industries, as they offer quality education and applied skill trainings. Moreover, as the industrial-university collaboration model has not yet been fully introduced, the proper curriculum settings, teaching methods and evaluation systems are not able to meet the needs of enterprises as intended. Therefore, changes in the supply and demand market have led to lack of stability and connectivity in majors and courses, which is not conducive to the development of local universities.

\section{Significance of the Collaborative Education Model of Local Universities under the Fundamentals of "New Engineering" Construction}

Firstly, we need to innovate the skill training mechanism to improve its quality. The industrialuniversity collaboration is the only way for local universities to realize the transformation and development of applied technology skill training. In the process of training talents such as classroom training, factory internship, school experimental training, and enterprise internship, the seamless connection and intercommunication of important links must be realized to effectively ensure the continuity and integrity of talents at all stages of learning, to establish a complete education system. Through the collaborative construction of skill sharing fundamentals, off-campus training bases and the combination of production, education and research, as well as through process management, performance sharing and responsibility sharing, an off-campus operation mechanism is formed. Secondly, it provides a good external environment for local colleges and universities to train new engineering and technical personnel. The training of new talents in local universities is a system involving multiple sub-systems, which need to be coordinated in a way that the industrial-university collaboration involves combinations of education disciplines to have many features. In addition, universities, research institutes and industries have unique skill training methods as well as resources to train highly innovative talents. This is to provide support, create synergy, and rely on other fields to jointly achieve the goal of developing high-level innovative talents. Finally, promoting the training of "dual professional" teachers through the collaboration of local colleges and universities and industrial-university collaboration leads to the highly educated and highly skilled personnel with high company work experience who mastered production technology, possessed practical training capabilities and provided independent guidance in the establishment of main courses. Therefore, to improve the professional quality of teachers, they are encouraged to participate in various forms of post graduate education, academic education and modern education skills training. Thus, the growth of teachers and the development of industrial production are completely integrated as well as combined with professional and synchronized theoretical techniques. (Note: Figure 1 local university industry cooperation and collaborative education model)

\subsection{Establishing a "new engineering subject" and focusing on the improvement and innovation of the skill training model}

With education improvement as the core, establishing a new skill training model helps consolidate the foundation of collaborative education. The school must conduct research and evaluate in all aspects of the skill training system including professional settings, practical training, professional certification, etc. Therefore, this creates a vision for the model of a high-quality skill training system which innovates the multilateral industrial-university collaborative education model. For instance, scientific research institutes, universities and local governments established a collaborative skill training model, which integrates skill training communities, multidisciplinary participation, production, education and research, as well as promotes industrial-university collaboration. 


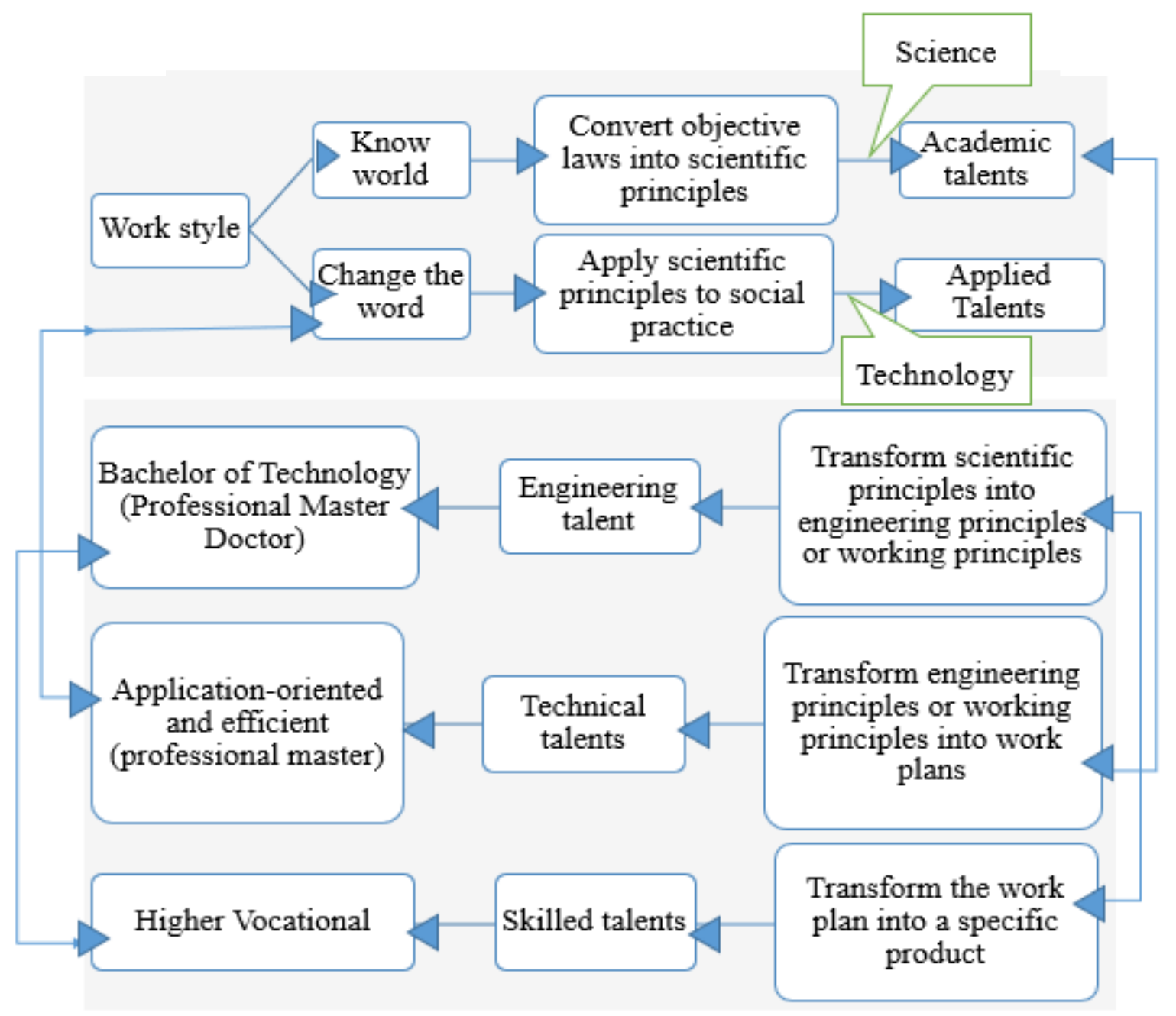

Figure 1. Local university industry cooperation and collaborative education model

4.2 Breaking the barriers of the traditional education system and establishing a scientific college curriculum system

In the era of new technologies and new industries, the aim is to develop "new engineering" talents whom grasp the latest development trends and explore the seamless connection of "lean production and intelligent manufacturing" through the construction of new systems. Nurturing talents that can accurately grasp new ideas, knowledge and technologies in the company as well as lay a solid foundation for the construction of a complete course chain can be achieved through a multidisciplinary comprehensive educational system. Moreover, a scientific and precise education chain has been formed and a comprehensive professional fundamental education system aimed to develop new technologies, industries and professional talents has been established. This was done by utilizing the company's excellent resources through a comprehensive active training course which was carried out to achieve system integration. Thus, the arrangement of various courses is scientific and relevant as well as completely integrated into a comprehensive course according to the learners cognitive abilities, which can be adapted for talents to increase their skill needs.

\subsection{Innovation of organizational development by local institutes under the fundamentals of "new engineering"}

Organizations are the products of specific social sectors and are independent of the needs of specific social areas. For instance, a university is a complex social organization, and its development cannot be separated from society. However, it is affected by 
various internal and external factors such as the relationship between universities and organizations which are gradually strengthening. Besides that, social organization, local colleges and universities must meet necessary social needs to perform important social tasks so as to increase the importance of social roles. In the context of the rapid development of the "new engineering" field, it was to adapt to the new requirements of social development allowing talents to continue to increase their understanding of construction and to strive to change and innovate the organizational structure.

\subsection{Changing the development models of local colleges and universities to meet the requirements of new methods and innovation- driven development}

The internal organization is reorganized according to their advancement in the industry, regional industry, regional economic development and school operation. This is based on the logical application to establish an organizational structure suitable for various external and internal resource sharing as well as establishment. For instance, external factors, such as government, industry and companies, strive to achieve collaboration and connections to achieve application-driven transformation as well as development. Local colleges and universities are demand-oriented. On the basis of coordination between schools and departments, local colleges can consider establishing industrial colleges to merge industrial model-related majors with modern industrial design majors, thus promoting the mutual promotion of vocational colleges and industrial universities. The function optimization is to provide innovation-driven services for local economic development through academic construction, talent training and applied research. The industrial college receives professional support mainly through professional environments and industry needs, course content and professional level, and professional development of education. Therefore, the effective connections with the process production can better meet the needs of local economic, social development, industrial transformation and upgrading, which emphasizes the characteristics of school operations as well as the importance of establishing an organizational structure that is highly consistent with organizational functions and goals.

\section{Conclusion}

In summary, the construction of the "new engineering" field is an important part of increasing the improvement of local colleges and universities as well as developing talents. In this case, it needs to be closely integrated with various educational disciplines to achieve the educational goals in the "new engineering" field which are establishing new talents and developing outstanding talents under the collaboration training mechanism. This article focuses on the improvement and innovation of the talent training model, the establishment of a scientific college education system, and the transformation of the development model of colleges and universities to promote the development of the collaborative education system of local colleges and universities under the fundamentals of the construction of "new engineering."

\section{Disclosure statement}

The author declares no conflict of interest.

\section{References}

[1]Cao, J., Wu, X., Hu, Y(2019). Practice of Network Engineering Curriculum Improvement based on Industry-University Cooperation under the Background of New Engineering Disciplines. Higher Education,(11): 63-65.

[2] Liu, L(2019). Research and Practice of Multiparty Collaborative Education Mode in Colleges and Universities under the Background of New Engineering. Business Situation,(40):223.

[3]Liu, J., Fen, H(2018). The Thinking and Practice of the Collaborative Education Training Model of Local Colleges and Universities under the "New Engineering." Education Modernization,5(52): 1013. 